\title{
Self-Paced and Video-Based Learning: Parent Training and Language Skills in Japanese Children with ASD
}

\author{
Ee Rea Hong and Liyuan Gong \\ University of Tsukuba \\ Jennifer B. Ganz \\ Texas A\&M University \\ Leslie Neely \\ University of Texas San Antonio
}

\begin{abstract}
While no exact information on the prevalence exists, it is assumed that the overall incidence of children with autism spectrum disorder (ASD) has risen every year in Japan. However, given the lack of resources and services for families of children with ASD in Japan, there is a dearth of practical guidance for the support for those families. This study examined the effects of an asynchronous training package (i.e., self-paced and video-based learning manual) to teach two Japanese mothers to implement incidental teaching. Effectiveness of the instruction was determined using a multiple-baseline design across mother-child dyads. Results indicated that the mother participants were able to implement the intervention with high fidelity over time. However, mixed effects of the mother-delivered intervention on target language behaviours were found across the child participants' behaviours. This study adds an evidence to support that parents can be essential and efficient intervention agents for children with $A S D$.
\end{abstract}

Approximately 6.2 per 1,000 individuals are identified as having a diagnosis of autism spectrum disorder (ASD) worldwide (Elsabbagh et al., 2012). ASD is a lifelong neurological disorder and characterized by difficulties in development of social- 
communication skills and by engagement in restrictive and repetitive behaviours and interests (American Psychiatric Association [APA], 2013). Most parents are likely to notice developmental and behavioural abnormalities, especially those in speech and language development of their children with ASD, before 2 years of age (De Giacomo \& Fombonne, 1998). Although many children with ASD tend to present such difficulties in common, they can present with significant variations in abilities ranging from individuals with severe language deficits (e.g., nonverbal) to those who have full verbal abilities but difficulty with prosody of speech (Smith, Mirenda, \& Zaidman-Zait, 2007). This considerable heterogeneity in children's language ability may lead to difficulties in determining the best way to improve language skills needed for daily living for children with ASD (Taylor, Maybery, Grayndler, \& Whitehouse, 2014). In addition, significant speech, language, and social delays can result in complex communication needs $(\mathrm{CCN})$, preventing children from gaining functional communication. It is estimated between 30 $50 \%$ of individuals with ASD never develop functional speech throughout their lifetime (Preston \& Carter, 2009). Lack of functional communication can lead to increased risk of poor academic performance, lower raters of employment, increased levels of challenging behaviour, and reduced social engagement (Lord, Risi, \& Pickles, 2004; Wilczynski, Trammell, \& Clarke, 2013).

\section{Incidental Teaching to Address Complex Communication Needs}

Research identifies behaviour analytic interventions, and in particular naturalistic models of early language development, as effective in facilitating the acquisition of language and communication for young children with ASD (Wong et al., 2015). Naturalistic language interventions consist of applied behaviour analysis (ABA)-based behavioural techniques and language learning strategies developed based on a social interactionist approach (Kaiser \& Trent, 2007). As one of the naturalistic language interventions, incidental teaching has been identified as an evidence-based practice as well as one of the most commonly used ABA-grounded methods for children with ASD (Behavior Analyst Certification Board, 2012; Wong et al., 2015). Incidental teaching is characterized by teaching trials occurring in the natural environment, and involves a communication partner following a child's lead and constructing communication opportunities in response to the child's initiations (McGee, Morrier, Daly, 1999). For example, if a child points toward a requested item, the communication partner might encourage communication by prompting a verbal response before reinforcing the child with the requested item. Communication opportunities can be planned in advanced using environmental arrangement (e.g., placing items in sight but out of reach), sabotage of an activity (e.g., providing food without utensils), or engagement in unexpected behaviours during a routine (e.g., pausing by the door without opening it).

\section{Communication Partners}

Since language and communication are ubiquitous, children with ASD require consistent support from all potential communication partners in order to learn new social and communication skills. For young children, communication partners are often parents, family members, or other caregivers. Family members and caregivers, while essential to 
the development of language, often engage in behaviours that are not conducive to language acquisition. For example, research identifies that communication partners often offer limited communication opportunities (Barker, Akaba, Brady, \& Thiemann-Bourque, 2013) or ignore the child's communication initiations (Sigafoos, 1999). Barker et al. (2013) and Sigafoos (1999) found that communication partners, including school teachers and facility staff, are likely to engage in more constructive social and communication interactions with children with ASD following systematic support. Although caregivers of children with ASD were not included in these two previous investigations, both studies discussed the need for further development of explicit and systematic training for caregivers to enable them to produce effective social and communication interactions with their children with ASD (see Barker et al., 2013; Sigafoos, 1999).

\section{Training Caregivers in Incidental Teaching}

Researchers have investigated a number of training strategies to prepare caregivers and other interventionists in variations of incidental teaching (e.g., Hsieh, Wilder, \& Abellon, 2011). Training procedures have included verbal and written instruction, live modeling, video-modeling, rehearsal, and feedback (Alpert \& Kaiser, 1992; CharlopChristy \& Carpenter, 2000; Hsieh et al., 2011; Laski, Charlop, \& Schreibman, 1988). For example, Hsieh et al. (2011) provided parents with a list of the steps necessary to implement incidental teaching, modeled the procedure, and then had the parents rehearse the procedure. Once each parent had practised three times, the trainer provided performance feedback. The rehearsal and feedback cycle continued until the parent performed $80 \%$ of the steps correctly for three consecutive sessions. Part of the supports were then systematically faded (e.g., list of steps necessary for incidental teaching). All of the parents improved their implementation of incidental teaching above baseline levels. During the intervention probes, each child participant also showed increases in their response.

While there is evidence that caregivers can effectively implement behaviour analytic interventions, all of the training was provided in real time (e.g., synchronously) either face to face or via telepractice. Synchronous training, while effective, may not be feasible in resource-constrained environments. For example, the prevalence of ASD in Japan is estimated between 37.5 (Honda, Shimizu, \& Rutter, 2005) to 181.1 (Kawamura, Takahashi, \& Ishii, 2008) per 1000 individuals. Unfortunately, there is a dearth of boardcertified behaviour analysts with a count of 17 as of 2018 (Behavior Analyst Certification Board, 2018). There is a need to evaluate innovative training procedures that do not require face-to-face or real-time meetings. The purpose of this study is to evaluate an asynchronous training package to teach two Japanese parents to implement incidental teaching. This study addresses the following research questions:

1. Would parents of children with ASD learn and implement incidental teaching procedures with acceptable fidelity, given a researcher-developed asynchronous training package?

2. Given the training, would children with ASD and $\mathrm{CCN}$ show improvement in their targeted language behaviours? 


\section{Method}

\section{Participants, Settings, and Materials}

Participants. Initially, three mother-child dyads participated in the study. The child participants included two boys aged 4 years, 3 months, and 5 years, 2 months; and one girl aged 4 years, 9 months. All three had an autism spectrum diagnosis by a licensed pediatrician prior to the study. The mother participants had no formal experience delivering behaviour analytic treatments to their children. All participants were individually recruited from a local university where the child participants had received behaviour therapy. At the time of the study, the child participants were attending one-onone behavioural treatment sessions (1 hour per week) offered at the university. The experimental procedures and methods for participant recruitment for this study were approved by the ethics committee of the University of Tsukuba in Japan. Informed consent was obtained from all mother participants. Participants were considered for this study if: (a) the child participant had a prior clinical diagnosis of ASD by a licensed pediatrician; (b) the child participant showed persistent deficits in language and/or communication behaviours; and (c) the mother participant expressed willingness to learn and implement the intervention procedures. The mother participants and the children's behavioural therapists at the university reported that all child participants presented deficits in language and communication skills. Additionally, the Kyoto Scale of Psychological Development 2001 (Ikuzawa, Matsushita, \& Nakase, 2002) was administered to all child participants. As a result of the assessment, all three participants showed a delay in the Language-Sociability domain of up to four years. Table 1 presents detailed participant characteristics for the child participants.

Settings. All sessions (i.e., pre-training, training, post-training, follow-up) were conducted in the living room of each participant's home setting.

Study Duration. A maximum of two to three sessions (5-minutes per session) took place weekly over 5 months (i.e., from Spetember 2016 to February 2017).

Materials. Various materials were selected based on the child participant's preference in each session. A description of the materials and activities selected for the child participants can be found in Table 1. All data collection sessions were videorecorded for analysis throughout the study. The mother participants were asked to save videos recorded from each session in a portable external hard drive and bring the hard drive to a weekly meeting with the first author. All instructions for pre-training, training, post-training, and follow-up sessions were delivered in PowerPoint slide format and stored in a portable external hard drive. The third mother-child dyad was dropped from the study because the mother participant expressed emotional distress over the duration of the study due to technology problems (e.g., video-recording, transferring videos to a hard drive). In addition, video-recording itself seemed to trigger the child's problem behaviours including temper tantrum and disobedience. 
Table 1

Participant Characteristics

\begin{tabular}{|c|c|c|c|c|c|}
\hline \multirow{2}{*}{$\begin{array}{l}\text { Child } \\
\text { Child A } \\
\text { Male } \\
\text { Age 4y3m }\end{array}$} & \multicolumn{3}{|c|}{$\begin{array}{c}\text { Developmental } \\
\text { Quotient } \\
\text { (KSPD: score, age) }\end{array}$} & \multirow{2}{*}{\begin{tabular}{l}
\multicolumn{1}{c}{$\begin{array}{c}\text { Communication } \\
\text { Characteristics }\end{array}$} \\
Non-verbal, no independent \\
functional communication, \\
using a hand gesture (i.e., \\
hand clapping) when \\
making a request for items \\
or activities, no eye contact.
\end{tabular}} & \multirow{2}{*}{ 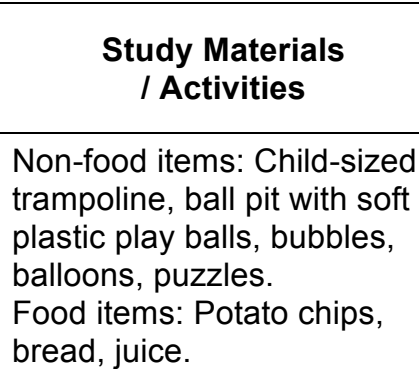 } \\
\hline & $\begin{array}{l}\text { Overall } \\
\text { PM } \\
\text { CA } \\
\text { LS }\end{array}$ & $\begin{array}{l}29 \\
38 \\
28 \\
24\end{array}$ & $\begin{array}{l}1 \mathrm{y} 5 \mathrm{~m} \\
1 \mathrm{y} 5 \mathrm{~m} \\
1 \mathrm{y} 5 \mathrm{~m} \\
1 \mathrm{y} 5 \mathrm{~m}\end{array}$ & & \\
\hline $\begin{array}{l}\text { Child B } \\
\text { Female } \\
\text { Age } 4 y 9 \mathrm{~m}\end{array}$ & $\begin{array}{l}\text { Overall } \\
\text { PM } \\
\text { CA } \\
\text { LS }\end{array}$ & $\begin{array}{l}59 \\
78 \\
51 \\
63\end{array}$ & $\begin{array}{l}2 \mathrm{y} 4 \mathrm{~m} \\
3 \mathrm{y} 1 \mathrm{~m} \\
2 \mathrm{y} 0 \mathrm{~m} \\
2 \mathrm{y} 6 \mathrm{~m}\end{array}$ & $\begin{array}{l}\text { One- to two-word functional } \\
\text { utterances, unresponsive to } \\
\text { others' requests, preferred } \\
\text { solitary play. }\end{array}$ & $\begin{array}{l}\text { Non-food items: Toy house } \\
\text { and figures, blocks. } \\
\text { Food items: Tangerine, } \\
\text { potato chips, cucumber. }\end{array}$ \\
\hline
\end{tabular}

Notes: Ages in years ( $\mathrm{y}$ ) and months ( $\mathrm{m})$.

KSPD, Kyoto Scale of Psychological Development 2001 (Ikuzawa, Matsushita, \& Nakase, 2002): Its component scales are PM, Physical-Motor; CA, Cognitive-Adaptive; LS, Language-Social.

\section{Procedures}

Pre-assessment. The mother participants met separately with the first author twice prior to the initiation of the study. These pre-assessment meetings lasted about one hour each. In the first meeting, the first author discussed the purpose of the study and reviewed the informed consent form. In addition, the mother participants were asked to list their children's preferred items and activities. The first author purchased all items and play materials identified in the first meeting; and in the second meeting, a digital video camcorder and play materials were provided to each mother-child dyad. The first author also provided the participants with a portable external hard drive that contained written and video instructions on how to conduct pre-training sessions.

Pre-training session. The purpose of the pre-training session was to evaluate the typical social and communicative interactions between the mother participants and their children. The mother participants were asked to review written and video instructions provided by the first author and to follow the procedures. The instructions were developed to provide the mother participants with information about how to select a setting, select items and activities, record videos, and save the videos in the hard drive. During this phase, the mother participants were asked to: (a) select one setting where their social and communicative interactions with their children would occur most frequently, such as living room, kitchen, or bedroom, (b) select items and activities based on the child's preference, (c) set up a camcorder and record sessions (two to three 5minute sessions per week), and (d) save videos in the hard drive.

Select target behaviours. The first author watched all pre-training videos and selected target behaviours for each mother-child dyad. As a primary target behaviour, the fidelity of the instructional procedures completed in each communication trial by the mother participants was evaluated in the study. As a secondary target behaviour, different behaviours were selected across the mother and child participants. Behaviours were 
targeted if the behaviours either occurred at low levels or did not occur during pretraining and were likely to be improved after the introduction of the intervention (see Table 2 for the behaviours targeted for each mother-child dyad). Prior to determining the target behaviours, Mother A indicated that she would prefer to target her child's verbal speech. Therefore, the target behaviours were determined based on each mother participant's preference as well as on the discussion with the child participants' behavioural therapists after the first author watched the videos recorded during the pretraining sessions. In a weekly meeting, the first author provided the mother participants with a rationale as to why such behaviours were selected for them and their children.

Table 2

\section{Operational Definitions of Each Target Behaviour Across the Parent-Child Dyads}

\begin{tabular}{|c|c|c|c|}
\hline \multicolumn{2}{|r|}{ Target Behaviours } & \multicolumn{2}{|r|}{ Target Behaviours } \\
\hline Child A & $\begin{array}{l}\text { 1. Verbal response: The child produces } \\
\text { the first vowel sound in a word. Two } \\
\text { responses are targeted, including } \\
\text { [a] for "I want more" (“やって } \\
\text { [Yatte]" in Japanese) and [o] for } \\
\text { "Give me" (“ちょうだい [Tyoudai]" in } \\
\text { Japanese). }\end{array}$ & Parent A & $\begin{array}{l}\text { 1. Accurate intervention } \\
\text { implementation: The parent } \\
\text { follows each step of the } \\
\text { intervention procedures } \\
\text { accurately. } \\
\text { 2. Communication opportunity: } \\
\text { The parent provides more than } \\
\text { three communication } \\
\text { opportunities (i.e., question } \\
\text { and answer) to the child within } \\
\text { each session. }\end{array}$ \\
\hline Child B & $\begin{array}{l}\text { 1. Two-word verbal response: When } \\
\text { asked a question, the child } \\
\text { produces a 2-word verbal response } \\
\text { directly related to the item or activity } \\
\text { that she is engaged in. } \\
\text { 2. Use of different words: When } \\
\text { responding to a question, the child } \\
\text { produces a verbal response that } \\
\text { consists of more than } 2 \text { different } \\
\text { words. }\end{array}$ & Parent B & $\begin{array}{l}\text { 1. Accurate intervention } \\
\text { implementation: The parent } \\
\text { follows each step of the } \\
\text { intervention procedures } \\
\text { accurately. } \\
\text { 2. Use of different words: } \\
\text { Expanding the child's current } \\
\text { level of communication by } \\
\text { presenting a sentence that } \\
\text { consists of more than } 3 \\
\text { different words. }\end{array}$ \\
\hline
\end{tabular}

Development of a training manual and self-paced learning session. In accordance with the target behaviours selected for each mother-child dyad, a training manual that consisted of written and video-based instructions was developed and provided to the mother participants. The purpose of the training manual was to provide the mother participants with instructions on how to have effective social and communication interactions with their children. The manual began with a brief introduction to incidental teaching and with some general directions for the training session. Following each experimental session, the mother participants were asked to complete a survey presented in the last part of the manual. Responses to each item in the survey were given on a 5point scale $(1=$ never, $2=$ rarely, $3=$ sometimes, $4=$ often, $5=$ every time $)$. This survey was used for self-reflection to facilitate each mother participant's self-learning after the completion of each experimental session. It should be noted that the mother participants 
might have skipped some procedural steps as they improved their skills over time. Figure 1 presents details on the general directions and survey questionnaire given to the mother participants.

Figure 1. General Directions for the Training Sessions

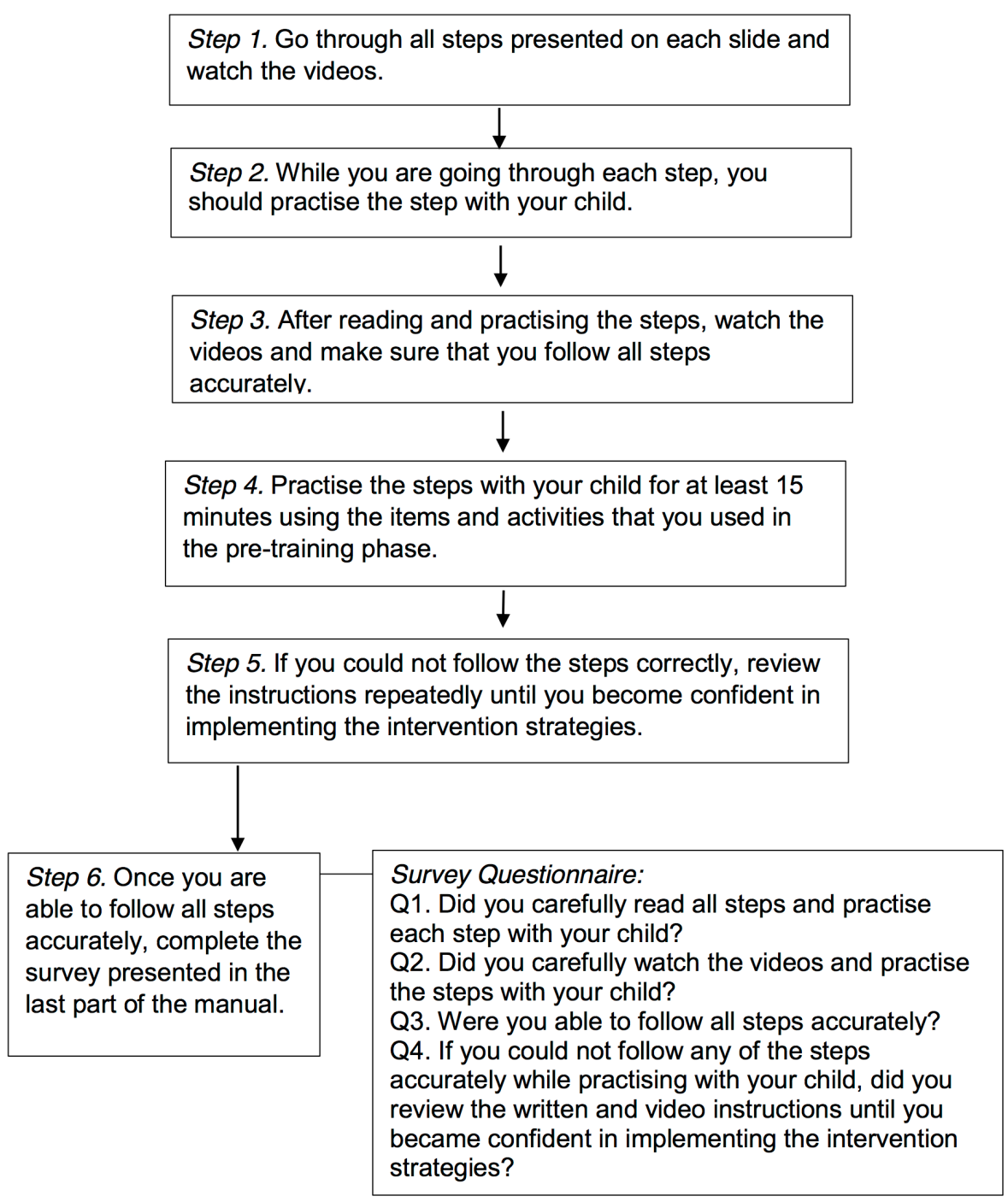

Following the above-mentioned instructions, each step of the intervention procedures was presented along with examples. The intervention procedures were modified according to the target behaviours determined for each mother-child dyad (see Table 3). The participants were instructed to practise the intervention techniques for two weeks. No specific number or duration of training sessions was mandated, since one purpose of the study was to examine whether self-paced learning could help caregivers independently acquire communication intervention strategies. Therefore, the total number or duration of training sessions was not calculated and might have varied slightly across the mother parent participants. During the second week of training, the first author met 
each mother participant and asked if she would feel confident implementing the intervention strategies with high fidelity.

\section{Table 3}

\section{Intervention Procedures for Each Parent-Child Dyad}

\begin{tabular}{|c|c|}
\hline & Teaching Procedures \\
\hline Step 1 & $\begin{array}{l}\text { Arrange the environment to encourage your child to socially interact with you. You } \\
\text { entice your child with items or activities that your child may prefer to increase his or } \\
\text { her motivation to socially communicate and interact with you. The items/activities } \\
\text { that your child prefers should be within the child's sight but out of his or her reach at } \\
\text { the beginning of each session. }\end{array}$ \\
\hline Step 2 & $\begin{array}{l}\text { Follow your child's lead and engage in the activity or items. If your child shows } \\
\text { interests in toy house and figures, make the items and activity playful as much as } \\
\text { possible. }\end{array}$ \\
\hline Step 3 & $\begin{array}{l}\text { Restrict access to the item/activity and ask a question directly related to the item or } \\
\text { activity that your child is engaged in. }\end{array}$ \\
\hline Parent A & $\begin{array}{l}\text { "Do you want more snack?", "Do you want to jump more?", or "Which one do you } \\
\text { want, juice or snack?" }\end{array}$ \\
\hline Parent B & $\begin{array}{l}\text { "What did you find?", "What is he (toy figure) doing", or "Which one do you want, } \\
\text { tangerine or cucumber?" }\end{array}$ \\
\hline Step 4 & $\begin{array}{l}\text { While restricting your child's access to the item/activity, wait } 3 \text { seconds for your } \\
\text { child to make a response before presenting an initial prompt. }\end{array}$ \\
\hline Step 5 & $\begin{array}{l}\text { After the } 3 \text { seconds of waiting, if your child does not display the targeted response, } \\
\text { present a prompt for communication. }\end{array}$ \\
\hline Parent A & $\begin{array}{l}\text { Verbal and physical prompts. Point to your child's mouth } 2 \text { to } 3 \text { times while } \\
\text { presenting a verbal prompt (i.e., saying [a] or [o]) for the targeted response. }\end{array}$ \\
\hline Parent B & $\begin{array}{l}\text { Verbal prompt only. Present a verbal prompt (i.e., 2-word prompt) for the targeted } \\
\text { response. }\end{array}$ \\
\hline Step 6 & $\begin{array}{l}\text { If your child displays the targeted response, provide one bite of food or access to } \\
\text { the item/activity for at least } 20 \text { seconds while adding a final model of responding } \\
\text { behaviour and expanding your child's current level of communication. }\end{array}$ \\
\hline Parent A & $\begin{array}{l}\text { Say “I want more” (“やって [Yatte]” in Japanese) or “Give me” (“ちょうだい } \\
\text { [Tyoudai]” in Japanese. }\end{array}$ \\
\hline Parent B & $\begin{array}{l}\text { Present a sentence that consists of more than } 3 \text { different words, such as "I found } \\
\text { sweet tangerine" or "He is reading a book". }\end{array}$ \\
\hline Step 7 & $\begin{array}{l}\text { If your child does not display the correct response after given the first prompt, } \\
\text { present another prompt for communication. }\end{array}$ \\
\hline Step 8 & $\begin{array}{l}\text { If your child does not display the correct response after given the second prompt, } \\
\text { present the final model of correct response and give a bite of food or access to the } \\
\text { item/activity that your child requests or engages in. }\end{array}$ \\
\hline Step 9 & Wait at least 2 to 3 seconds between prompts. \\
\hline
\end{tabular}

Post-training session and delayed feedback. Before initiating the post-training session, mother participants received a manual that included instructions concerning the post-training phase and multiple hard copies of self-evaluation checklist sheet. Procedures similar to the pre-training phase were followed, except that the first author 
provided delayed feedback to each mother participant according to the intervention procedure. Both verbal and written feedback were given to each mother participant. In a weekly meeting, the first author provided each mother participant with verbal feedback regarding the mother's performance. After the meeting, the first author also emailed the mother participants a list of comments discussed at the meeting. The mother participants were also asked to complete the self-evaluation checklist to assess their own performance in each session. If the mother participant conducted three experimental sessions over a week, she should have completed three evaluation forms. The self-evaluation form listed each step of teaching procedures, modified according to the behaviours targeted for each parent-child dyad.

Follow-up. Maintenance probes occurred one month following the conclusion of the post-training condition. Procedures were identical to the post-training procedures. However, no feedback was provided to the mother participants during this phase, and the mother participants were not asked to complete the self-evaluation checklist.

\section{Research Design}

A multiple-baseline design across participants (Kazdin, 2011) was used to assess the effects of self-paced and video-based learning on acquisition and maintenance of incidental teaching procedures across the mother participants. In addition to collecting data on the mother participants' performance, the predetermined targeted language behaviours of each child participant were also evaluated as a distal measure. See Figure 2 for a timeline depicting how the experimental design was implemented.

Figure 2. Timeline of the Experimental Procedures

\begin{tabular}{|c|c|c|c|c|c|c|}
\hline & 2016-09 & 2016-10 & 2016-11 & 2016-12 & 2017-01 & 2017-02 \\
\hline \multirow{2}{*}{ Mother A } & $\begin{array}{l}\text { Pre- } \\
\text { training }\end{array}$ & & \multirow{2}{*}{\multicolumn{2}{|c|}{ Post-training }} & & \multirow{2}{*}{$\begin{array}{l}\text { 1-month } \\
\text { follow-up }\end{array}$} \\
\hline & ק............... & $\begin{array}{l}\text { Training } \\
\text { session } \\
\end{array}$ & & & $\begin{array}{l}\text { Winter } \\
\text { recess }\end{array}$ & \\
\hline \multirow{2}{*}{ Mother B } & $\begin{array}{l}\text { Pre- } \\
\text { training }\end{array}$ & & \multirow{2}{*}{\multicolumn{2}{|c|}{ Post-training }} & & \multirow[t]{2}{*}{$\begin{array}{l}\text { 1-month } \\
\text { follow-up }\end{array}$} \\
\hline & ........ & $\begin{array}{l}\text { Tra } \\
\text { ses }\end{array}$ & & & $\begin{array}{l}\text { Winter } \\
\text { recess }\end{array}$ & \\
\hline
\end{tabular}




\section{Dependent Variables and Data Collection}

The parent participants. As the primary measure, each mother participant's performance was calculated for each trial during a 5-minute observation session by dividing the number of procedural steps implemented correctly by the total possible steps (9), multiplied by 100 (see Table 3 for the treatment procedural steps). If the child participants were given a question related to the item or activity that he or she requested or engaged in at the moment of observation (e.g., "Do you want to jump more?", "What did you find?", "What are you playing with?"), it counted as an experimental trial. As the secondary measure, the frequency of communication opportunities offered to their children was measured for Mother A. For Mother B, she was instructed to use varied words, at least one or two different words added to the child's response, to expand the child's current level of language skill when implementing the last step of the procedures (e.g., "You are eating sweet tangerine," if the child said, "Eating tangerine"). The mean number of different words that the mother participant spoke during a 5-minute session was calculated.

The child participants. Data were collected on the frequency of targeted responses displayed by the child participants within each session, and the results were expressed as a percentage. For each session, the total number of child responses was divided by the total number of communication opportunities given and multiplied by 100 to obtain a percentage. For Child B, in addition to collecting data on the targeted verbal responses, the mean number of different words that she produced within each session was measured. Operational definitions for each of the target behaviours are given in Table 2.

\section{Social Validity}

Following the completion of the study, the mother participants completed a brief survey that consisted of seven questions adapted from the Client Satisfaction Questionnaire (CSQ; Larsen, Attkisson, Hargreaves, \& Nguyen, 1979). A 5-point Likerttype scale was used $(5=$ strongly agree or very good, $4=$ agree or good, $3=$ neutral, $2=$ disagree or somewhat poor, 1 = strongly disagree or very poor). The Appendix presents details of the survey distributed to the mother participants. The average social validity rating was 4.1 ranging from 4 to 5 . Additionally, both mother participants did indicate in the open comments that they found the self-paced and video-based learning to be effective and would continue using the intervention strategies with their children. However, one of the participants also mentioned that she was often confused with the number of prompts that she should have provided in each trial.

\section{Procedural Integrity and Reliability}

Inter-observer agreement data were collected for the mother participants' fidelity of implementation and the child participants' responses by two independent observers. Data were collected for each mother-child dyad for a minimum of $25 \%$ of all sessions within each phase (i.e., pre-training, post-training, and follow-up). Point-by-point agreement was used to calculate reliability. In this study, the accuracy of the mother participants' intervention implementation is considered as procedural integrity. For procedural integrity, two observers independently coded the procedural integrity data from video 
recordings of all sessions. The average reliability for all sessions throughout the study was $94 \%$, ranging from $91 \%$ to $100 \%$ across the mother participants. For the child participants' responses, the average reliability for all sessions across the participants was found to range from $75 \%$ to $100 \%$ with an average of $97 \%$.

\section{Results}

Overall, visual analysis of the data suggests a positive effect of the treatment teaching strategies, self-paced plus video-based learning, on the accuracy of intervention implementation of the mother participants, while there was no functional relation demonstrated given only two replications of effect. Furthermore, mixed effects of the mother-delivered intervention on target language behaviours were found across the child participants' behaviours. Figure 3 presents the effects of self-paced and video-based learning on mother behaviours during pre-training, post-training, and follow-up phases. Figure 4 displays the effects of mother-delivered intervention on language behaviours of each child participant.

\section{Parent Behaviours}

Percentage of the accuracy of intervention implementation. To answer the first research question (i.e., Would parents of children with ASD learn and implement incidental teaching procedures with acceptable fidelity over time, given the researcherdeveloped self-paced and video-based learning manual?), we used a multiple-baseline design across mother participants and visually analyzed graphed data for each target behaviour. The percentage of intervention procedures that were accurately implemented by each mother participant is displayed as the gray bars in Figure 3 and corresponds to the left $y$-axis. Prior to training, the mothers' implementation of the intervention procedures remained at a low level across both mother participants. Across all pretraining sessions, mean percentages of accurate intervention implementation were $0 \%$ and 47\% (range 37.9-53.3\%), respectively, for Mother A and B. During the post-training sessions, there was an immediate and substantial increase in the percentage of accurate intervention implementation for Mother A $(M=92.9 \%$, range 83.3-100\%). Meanwhile, a moderate but steady improvement in the accuracy of intervention implementation was observed in Mother B throughout the training sessions $(M=92.5 \%$, range $61.1-100 \%)$. At the 1-month follow-up sessions, a slight decrease was observed in Mother A $(M=89.6 \%$, range 83.3-100\%), through still above baseline levels, while Mother B continued to implement the intervention procedures with a high degree of accuracy $(M=92.3 \%$, range $89.4-97.9 \%)$.

Additional measures: The number of communication opportunities and mean number of different words used. In addition to the accuracy of intervention implementation, the number of communication opportunities offered by Mother A was also measured. The results are shown as open circles in the first in Figure 3 and correspond to the right $y$-axis. Prior to training, Mother A provided none or a small number of communication opportunities during all pre-training sessions. Upon training, there was an immediate increase in the number of communication opportunities offered $(M=4.5$, range $2-8)$. Depending on the activity that Child A engaged in during each 
session, the number of communication opportunities differed throughout the post-training sessions. For example, Mother A tended to offer her child more communication opportunities when using food items, such as potato chips or juice, than with toys, since Child A was given only a piece of food and consumed it in a short time (10 seconds or less). In contrast, during physical activities, including jumping on a trampoline or playing inside a ball pit with soft plastic balls, fewer communication opportunities tended to be given to the child, since each trial took relatively longer than the food-based activity (20 seconds or more). At follow-up, Mother A offered 4.3 communication opportunities on average (range 2-6).

Figure 3. Results: Parent Participants

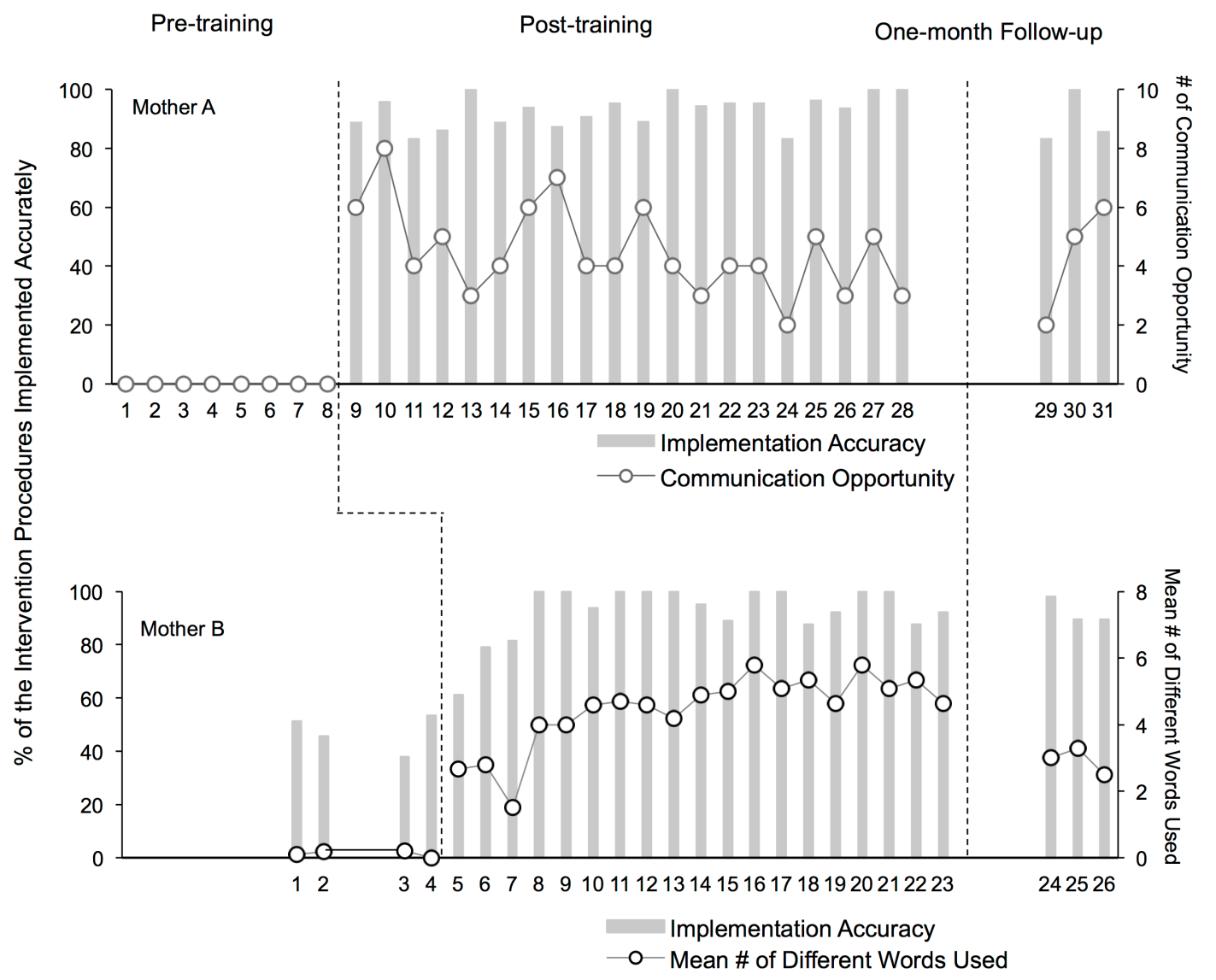

The number of different words that Parent B used to expand Child B's current level of language skill was additionally measured (Step 6, see Table 3). For Child B, two-word verbal response was measured as a target behaviour; and therefore, Parent B was asked to present more than three different words in a sentence when implementing Step 6. The results are shown as open circles in the second tier in Figure 3 and correspond to the right $y$-axis. Prior to training, Parent B tended to repeat the exact words that Child B had produced or did not provide any verbal feedback to the child's targeted behaviour $(M=0.1$, range $0-0.2)$. Across the post-training sessions, there was a steady increase in the number of different words used $(M=4.4$, range 1.5-5.7). At follow-up, there was a 
small decrease observed in the number of different words used by Parent B $(M=2.9$, range 2.5-3.2).

\section{Child Behaviours}

To answer the second research question (i.e., Given the training, would children with ASD and CCN show improvement in their targeted language behaviours?), we visually analyzed graphed data for each target behaviour. Generally, positive effects of parent use of intervention strategies on child use of target responses were observed for both child participants, as shown in Figure 4. For Child A, verbal response was targeted. The percentage of verbal response made by Child $\mathrm{A}$ is displayed as the open squares in the first tier in Figure 4 and corresponds to the left $y$-axis. As can be seen, there was no significant improvement in the targeted behaviour detected throughout the post-training $(M=1.2 \%$, range $0-25 \%)$ and follow-up sessions following treatment. However, Mother A reported that Child A increased his eye contact throughout the post-training and follow-up sessions.

Figure 4. Results: Child Participants

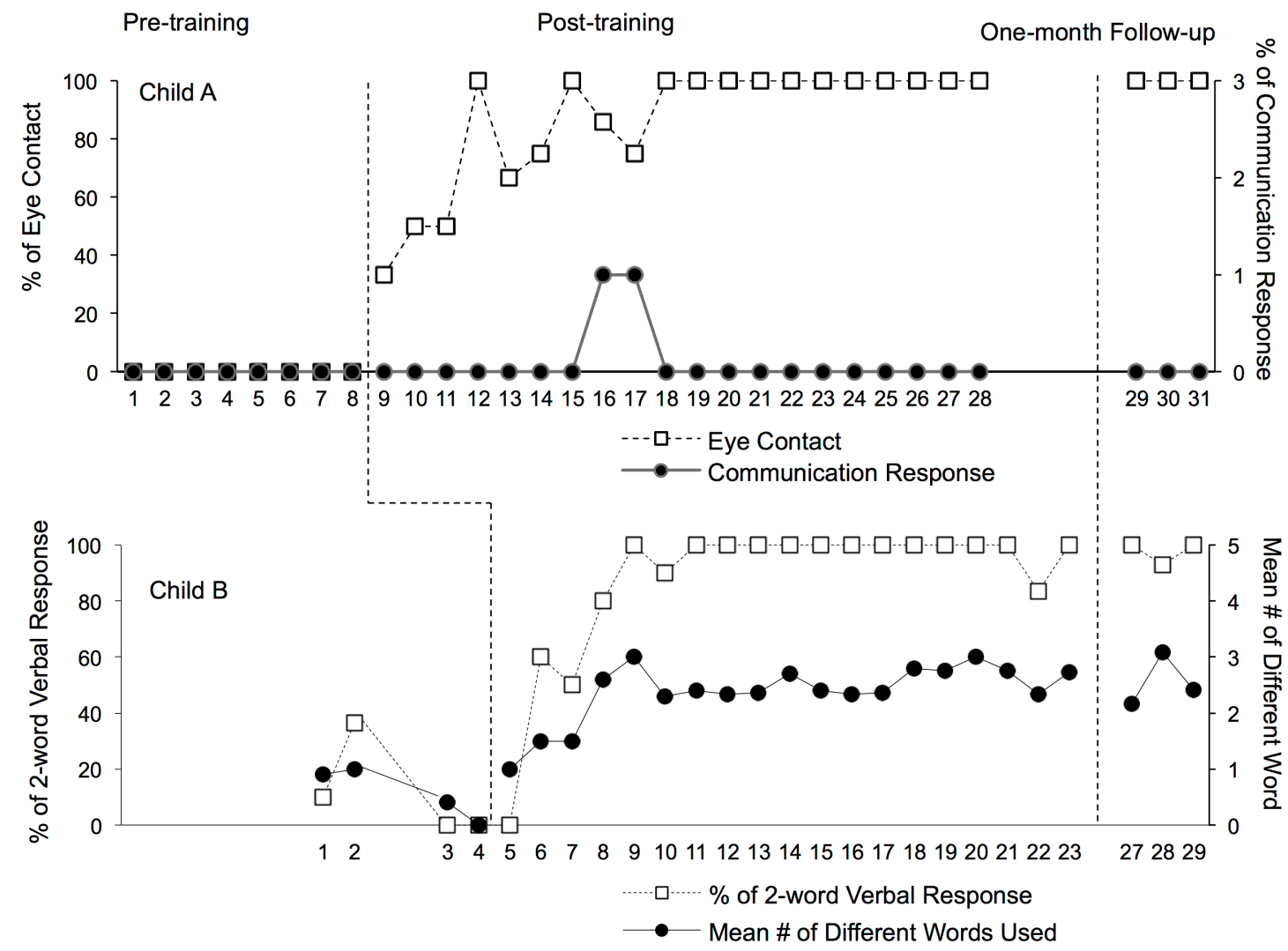

For Child B, two language behaviours including two-word verbal response and the number of different words used when responding to questions posed by her mother were targeted for intervention. Prior to treatment, Child B tended to produce a one-word 
verbal response when asked a question related to the object or activity that she engaged in within each trial $(M=11.5 \%$, range $0-36.3 \%)$. Following treatment, Child B increased the use of two-word verbal response to a mean of $87.5 \%$ per session (range $0-100 \%$ ). At follow-up, she continued to produce the targeted response on an average of $97.6 \%$ (range $92.3-100 \%$ ). The results are displayed as the open squares in the second tier in Figure 4 and correspond to the left $y$-axis. Since Child B's language use was limited - mainly one-word responses - the use of different words uttered by Child $\mathrm{B}$ when responding to a question posed by her mother was also targeted. The results are shown as the closed circles in Figure 4 and correspond to the right $y$-axis. During pretraining, Child B appeared to produce one-word verbal responses $(M=0.5$, range $0-1)$. She increased the use of different words to a mean of 2.3 per session (range 1-3) during the post-training sessions, and this gain was maintained throughout the 1-month followup $(M=2.5$, range $2.1-3)$.

\section{Discussion}

The primary purpose of this study was to evaluate the effectiveness of an asynchronous training package (i.e., self-paced and video learning instruction) on mothers' acquisition and maintenance of incidental teaching procedures. Overall, the results of this study are promising despite the loss of the third dyad, preventing us from making a statement regarding the presence of a functional relation. Both of the mother participants who completed the study made at least moderate improvements in their implementation of the intervention steps and their individualized targets: number of communication opportunities provided (Mother A) and number of novel words used (Mother B). These improvements were maintained by both mothers 1 month after completion of the post-training phase at levels either similar to the post-training phase or nearly so (e.g., number of novel words used for Mother B) and well above performance in pre-training. Given the increasing prevalence of ASD as well as the lack of ASD interventionists in Japan, this study provides additional research support for the effectiveness of parent training using self-paced and video-based learning in the field of autism. It revealed positive and socially valid results for an asynchronous training package implemented by parents of children with ASD. It also revealed that parents could maintain their acquired skills over time without continuous assistance from professionals. These results are consistent with previous research identifying parents as essential and efficient intervention agents for children with ASD (e.g., Acar, Tekin-Iftar, \& Yikmis, 2017; Chaabane, Alber-Morgan, \& DeBar, 2009). In addition, this study extends prior research that included in vivo or telepractice parent training (Alpert \& Kaiser, 1992; Charlop-Christy \& Carpenter, 2000; Hsieh et al., 2011; Laski et al., 1988) by modifying much of the training to be delivered asynchronously with an element of self-reflection for the parents.

The second purpose of this study was to assess the distal effects of training parents in incidental teaching on the targeted language behaviours of the child participants. Results for distal behaviours were somewhat mixed. Both children made moderate or strong improvements in most target behaviours, with the exception of verbalizations for

Child A. These results were maintained at the 1-month follow-up for both child participants. Because only a portion of the prior literature on parent training reported 
results for child participants or vice versa (e.g., Chaabane, Alber-Morgan, \& DeBar, 2009; Ingersoll \& Gergans, 2006), this extends the literature base with regard to the child behaviours, which are the outcomes of most interest to parents and practitioners.

\section{Limitations}

Although promising, this study has some limitations. One, as mentioned above, is that one of the dyads dropped out of the study. Our design, without a third tier, does not qualify as a high-quality single-case experimental design and; therefore, we are unable to confidently state that the intervention was effective. Two, information was unavailable regarding the mothers' self-study in terms of number of hours spent reading the materials, practising, and reviewing materials prior to data collection. Thus, we are unsure of the dosage of the intervention each mother participant received, which makes this difficult to duplicate. Three, although the mother participants showed significant improvement in the accuracy of implementation of the intervention procedures, it should be noted that some improvement might have been obtained as they went through the training over the experimental period. This raises the question of whether or not personal biases were avoided when the mother participants were implementing the intervention procedures. We conclude that even when utilizing asynchronous training, a more systematic approach should be employed to closely observe parents' performances in a home setting.

\section{Implications for Practice}

This study has a number of implications, if the results can be replicated with a stronger study design. First, language and communication behaviours are best taught in natural environments by natural communication partners for a number of reasons. Because language and communication are ubiquitous, they must be targeted across almost every setting and context the child attends. Further, because parents and caregivers are typically the individuals who spend the most time with their children on weekly and lifelong bases, it is crucial that they be included in interventions for their own children, thus enabling them to capitalize on natural communication opportunities and to advocate for best practices for their children in the future. Second, telepractice behavioural intervention is becoming more commonplace out of necessity for cases in which parents have minimal or no access to highly qualified behavioural therapists because they live in rural areas or places where few certified behaviour therapists live. This study assessed the outcomes of a blended format of synchronous and asynchronous instruction. If successful, this would provide opportunities to families who cannot easily access training and who cannot commit to attend training during regular work hours due to competing responsibilities. The asynchronous component allows parents to learn when they are able to find time in their schedules, such as evenings and weekends.

\section{Implications for Research}

Future research may focus on a number of related dimensions of this study. One, the blended telepractice format should be replicated with stronger designs. Two, data should be collected from the parents regarding how many hours they spend engaging with the 
intervention materials. This will enable further development of this intervention with regard to the most effective instructions that should be given to the parents. Three, research could evaluate the effects if parents are asked to self-evaluate with a more structured format and to begin implementation only when they have met a pre-determined criterion for implementation fidelity. Video self-analysis could be one component of this, in which parents record videos of themselves and self-assess their performance with a structured checklist of intervention components and setting goals for improvement. Four, at least one of the child participants in this study might have been a good candidate for use of augmentative and alternative communication, particularly Child A, who did not increase verbalizations during the study. Therefore, future research could incorporate instruction for the parents regarding how to incorporate augmentative and alternative communication within this protocol.

\section{References}

Acar, C., Tekin-Iftar, E., \& Yikmis, A. (2017). Effects of mother-delivered social stories and video modeling in teaching social skills to children with autism Spectrum disorders. The Journal of Special Education, 50, 215-226. doi:10.1177/0022466916649164

Alpert, C. L., \& Kaiser, A. P. (1992). Training parents as milieu language teachers. Journal of Early Interventions, 16, 31-52. doi:10.1177/105381519201600104

American Psychiatric Association. (2013). Diagnostic and statistical manual of mental disorders (5th edition; DSM-5). Washington, DC: Author.

Barker, R. M., Akaba, S., Brady, N. C., \& Thiemann-Bourque, K. (2013). Support for AAC use in preschool, and growth in language skills for young children with developmental disabilities. Augmentative and Alternative Communication, 29, 334-346. doi:10.3109/07434618.2013.848933

Behavior Analyst Certification Board. (2012). Fourth edition task list. Retrieved from https://www.bacb.com/wp-content/uploads/2017/09/160101-BCBA-BCaBA-task-list-fourthedition-english.pdf

Behavior Analyst Certification Board. (2018). BCBA/BCaBA registry. Retrieved from http://info.bacb.com/o.php?page $=100155 \&$ by $=$ country

Chaabane, D. B. B., Alber-Morgan, S. R., \& DeBar, R. M. (2009). The effects of parent-implemented PECS training on improvisation of mands by children with autism. Journal of Applied Behavior Analysis, 42, 671-677. doi:10.1901/jaba.2009.42-671

Charlop-Christy, M. H., \& Carpenter, M. H. (2000). Modified incidental teaching sessions: A procedure for parents to increase spontaneous speech in their children with autism. Journal of Positive Behavior Interventions, 2, 98-112. doi:10.1177/109830070000200203

De Giacomo, A., \& Fombonne, E. (1998). Parental recognition of developmental abnormalities in autism. European Child \& Adolescent Psychiatry, 7, 131-136. doi:10.1007/s007870050058

Elsabbagh, M., Divan, G., Koh, Y. J., Kim, Y. S., Kauchali, S., Marcín, C., .. Yasamy, M. T. (2012). Global prevalence of autism and other pervasive developmental disorders. Autism Research, 5, 160-179. doi:10.1002/aur.239

Honda, H., Shimizu, Y., \& Rutter, M. (2005). No effect of MMR withdrawal on the incidence of autism: A total population study. Journal of Child Psychology and Psychiatry, 46, 572-579. doi:10.1111/j.1469-7610.2005.01425.x 
Hsieh, H. H., Wilder, D. A., \& Abellon, O. E. (2011). The effects of training on caregiver implementation of incidental teaching. Journal of Applied Behavior Analysis, 44, 199-203. doi:10.1901/jaba.2011.44-199

Ikuzawa, M., Matsushita, Y., \& Nakase, A. (2002). Kyoto scale of psychological development 2001. Kyoto, Japan: International Social Welfare Exchange Centre.

Ingersoll, B., \& Gergans, S. (2007). The effect of a parent-implemented imitation intervention on spontaneous imitation skills in young children with autism. Research in Developmental Disabilities, 28, 163-175. doi:10.1016/j.ridd.2006.02.004

Kawamura, Y., Takahashi, O., \& Ishii, T. (2008). Reevaluating the incidence of pervasive developmental disorders: Impact of elevated rates of detection through implementation of an integrated system of screening in Toyota, Japan. Psychiatry and Clinical Neurosciences, 62, 152-159. doi:10.1111/j.1440-1819.2008.01748.x

Kazdin, A. E. (2011). Single-case research designs: Methods for clinical and applied settings. New York, NY: Oxford University Press.

Kaiser, A. P., \& Trent, J. A. (2007). Communication intervention for young children with disabilities: Naturalistic approaches to promoting development. In S. L. Odom, R. H. Horner, M. E. Snell, \& J. Blacher (Eds.), Handbook of developmental disabilities (pp. 224-246). New York, NY: Guilford Press.

Laski, K. E., Charlop, M. H., \& Schreibman, L. (1988). Training parents to use the natural language paradigm to increase their autistic children's speech. Journal of Applied Behavior Analysis, 21, 391-400. doi:10.1901/jaba.1988.21-391

Larsen, D. L., Attkisson, C. C., Hargreaves, W. A., \& Nguyen, T. D. (1979). Assessment of client/patient satisfaction: Development of a general scale. Evaluation and Program Planning, 2, 197-207. doi:10.1016/0149-7189(79)90094-6

Lord, C., Risi, S., \& Pickles, A. (2004). Trajectory of language development in autistic spectrum disorders. In M. Rice \& S. Warren (Eds.), Developmental language disorders: From phenotypes to etiologies (pp. 7-29). Mahwah, NJ: Lawrence Erlbaum.

McGee, G. G., Morrier, M. J., \& Daly, T. (1999). An incidental teaching approach to early intervention for toddlers with autism. Journal of the Association for Persons with Severe Handicaps, 24, 133-146. doi:10.2511/rpsd.24.3.133

Preston, D., \& Carter, M. (2009). A review of the efficacy of the picture exchange communication system intervention. Journal of Autism and Developmental Disorders, 39, 1471-1486. doi:10.1007/s10803-009-0763-y

Sigafoos, J. (1999). Creating opportunities for augmentative and alternative communication: Strategies for involving people with developmental disabilities. Augmentative and Alternative Communication, 15, 183-190. doi:10.1080/07434619912331278715

Smith, V., Mirenda, P., \& Zaidman-Zait, A. (2007). Predictors of expressive vocabulary growth in children with autism. Journal of Speech, Language, and Hearing Research, 50, 149-160. doi:10.1044/1092-4388(2007/013)

Taylor, L. J., Maybery, M. T., Grayndler, L., \& Whitehouse, A. J. (2014). Evidence for distinct cognitive profiles in autism spectrum disorders and specific language impairment. Journal of Autism and Developmental Disorders, 44, 19-30. doi:10.1007/s10803-013-1847-2

Wilczynski, S. M., Trammell, B., \& Clarke, L. S. (2013). Improving employment outcomes among adolescents and adults on the autism spectrum. Psychology in the Schools, 50, 876-887. doi:10.1002/pits. 21718 
Wong, C., Odom, S. L., Hume, K. A., Cox, A. W., Fettig, A., Kucharczyk, S., ... Schultz, T. R. (2015). Evidence-based practices for children, youth, and young adults with autism spectrum disorder: A comprehensive review. Journal of Autism and Developmental Disorders, 45, 1951-1966. doi:10.1007/s10803-014-2351-z

\section{Authors' Note}

This work was supported by JSPS KAKENHI Grant Number JP16K20944.

Correspondence concerning this article should be addressed to Ee Rea Hong, Faculty of Human Sciences, University of Tsukuba, 1-1-1 Tennodai, Tsukuba, Ibaraki, 305-8577, Japan. Email: irehong@human.tsukuba.ac.jp 


\section{Appendix}

\section{The Caregiver Satisfaction Questionnaire (CSQ: Modified version)}

Please help me improve the training system by answering some questions about the training you have received through this research activity. I am interested in your honest opinions, whether they are positive or negative. Please answer all of the questions. I also welcome your comments and suggestions. Thank you very much, I appreciate your help.

\section{CIRCLE YOUR ANSWER}

1. How would you rate the quality of training you received?

2. Did you get the kind of training you wanted?

3. If a friend works with a child whose characteristics are similar with your child, would you recommend this training to $\mathrm{him} / \mathrm{her}$ ?

4. Has the training you received helped you to deal more effectively with your child?

5. In an overall, general sense, how satisfied are you with the training you received?

6. I believe this approach is likely to result in permanent improvement.

7. If you were to seek help again, would you come back to this training?

\begin{tabular}{|c|c|c|c|c|}
\hline $\begin{array}{c}\mathbf{1}= \\
\text { Strongly } \\
\text { Disagree or } \\
\text { Very Poor }\end{array}$ & $\begin{array}{c}2 \mathbf{2} \\
\text { Disagree } \\
\text { or Poor }\end{array}$ & $\begin{array}{c}\mathbf{3}= \\
\text { Neutral }\end{array}$ & $\begin{array}{c}4= \\
\text { Agree } \\
\text { or Good }\end{array}$ & $\begin{array}{c}\mathbf{5}= \\
\text { Strongly } \\
\text { Agree or } \\
\text { Very Good }\end{array}$ \\
\hline 1 & 2 & 3 & 4 & 5 \\
\hline 1 & 2 & 3 & 4 & 5 \\
\hline 1 & 2 & 3 & 4 & 5 \\
\hline 1 & 2 & 3 & 4 & 5 \\
\hline 1 & 2 & 3 & 4 & 5 \\
\hline 1 & 2 & 3 & 4 & 5 \\
\hline 1 & 2 & 3 & 4 & 5 \\
\hline
\end{tabular}

\section{WRITE COMMENTS BELOW:}

